\title{
Severe dysphagia associated with major tranquillizer treatment
}

\author{
T.A.T. Hughes, G. Shone' ${ }^{1}$ G. Lindsay ${ }^{2}$ and C.M. Wiles
}

Department of Neurology and 'Department of Ear Nose and Throat Surgery, University Hospital of Wales, Heath Park, Cardiff CF4 $4 \mathrm{XW}$, and ${ }^{2}$ General Practitioner, 350 Cyncoed Road, Cardiff, UK

\begin{abstract}
Summary: A 56 year old patient with psychiatric complications of systemic lupus erythematosus developed severe dysphagia complicated by weight loss and aspiration. Following investigation it was concluded that the addition of haloperidol to her treatment was the major precipitating cause and withdrawal of the drug was followed by an objective improvement in swallowing. Patients taking major transquillizers may be at increased risk of severe dysphagia; regular observation of swallowing is suggested as a useful addition to the clinical examination of these patients.
\end{abstract}

\section{Introduction}

Dysphagia is a recognized complication of idiopathic Parkinson's disease but it is not widely appreciated that significant dysphagia may also occur in drug-induced parkinsonism and in other syndromes associated with major tranquillizers.

\section{Case report}

In 1976 a 41 year old woman presented with discoid lupus confirmed on skin biopsy and was treated successfully with topical steroids. In 1984 she presented with agitated depression with some psychotic features and required admission to hospital. She improved with flupenthixol $20 \mathrm{mg}$ every 2 weeks. In December 1990 she presented with weight loss, malaise and myalgia. Investigations included haemoglobin $(\mathrm{Hb}) 7.1 \mathrm{~g} / 1$, platelets $132 \times 10^{9} / 1$, white blood cell count $2.4 \times 10^{9} / 1$, ESR $78 \mathrm{~mm}$ in one hour, anti-nuclear factor (ANF) of $1 / 320$, antibody to double-stranded DNA (antiDNA) of $1 / 320$ and subnormal levels of complement C3 and C4. A diagnosis of systemic lupus erythematosus (SLE) was made and she responded well to prednisolone and azathioprine. In December 1991 she became hyperactive with impaired memory and judgement, and required hospital admission for worsening agitation and paranoia. There was no evidence of active SLE and her symptoms were eventually controlled with medication; drugs prescribed on discharge in March 1992 were flupenthixol 20 mg every 2 weeks, procyclidine $5 \mathrm{mg}$ three times a day, haloperidol

Correspondence: T.A.T. Hughes, M.R.C.P.

Accepted: 10 January 1994
$1.5 \mathrm{mg}$ and diazepam $10 \mathrm{mg}$ four times a day, prednisolone $15 \mathrm{mg}$ daily and azathioprine $25 \mathrm{mg}$ three times a day.

In June 1992, whilst still on the medication listed above, she presented with an 8 week history of worsening, intermittent, painless dysphagia for solids and liquids with accompanying weight loss of $10 \mathrm{~kg}$. She had no other specific complaints. There was no other past medical history of note. She was a retired schoolteacher, married with two children and had no family history of neurological or psychiatric disease.

On admission she weighed $33 \mathrm{~kg}$, was clearly malnourished but walked unaided. She had marked postural hypotension and inspiratory crackles were audible at the left lung base; abdominal examination was normal. She was agitated and restless. Cranial nerve examination revealed a lack of facial expression, but palatal and pharyngeal sensation and reflexes were normal and tongue movements were normal. She had a quiet hoarse voice with a persistent productive cough and on attempting to drink water she coughed violently during and after the first mouthful and was unable to proceed. She had cogwheel rigidity and some bradykinesia in the limbs but no other neurological signs.

Investigations revealed a normochromic normocytic anaemia with $\mathrm{Hb} 10.7 \mathrm{~g} / 1$, ESR $70 \mathrm{~mm} /$ hour, C-reactive protein (CRP) $116 \mathrm{mg} / \mathrm{l}$ (normal range 1-4), normal complement levels, normal chest $X$-ray, negative ANF and a negative anti-DNA. A computerized tomographic scan of the brain and cerebrospinal fluid examination were normal. Indirect laryngoscopy showed chronic inflammation of the larynx, pooling of secretions and saliva in the pyriform fossae but normal move- 
ments of the vocal cords. Videofluoroscopy showed complete failure of laryngeal elevation and closure, and failure of cricopharyngeal opening. Pooling occurred in the pyriform fossae and above the cricopharyngeus, and there was aspiration of contrast into the larynx and trachea (Figure 1).

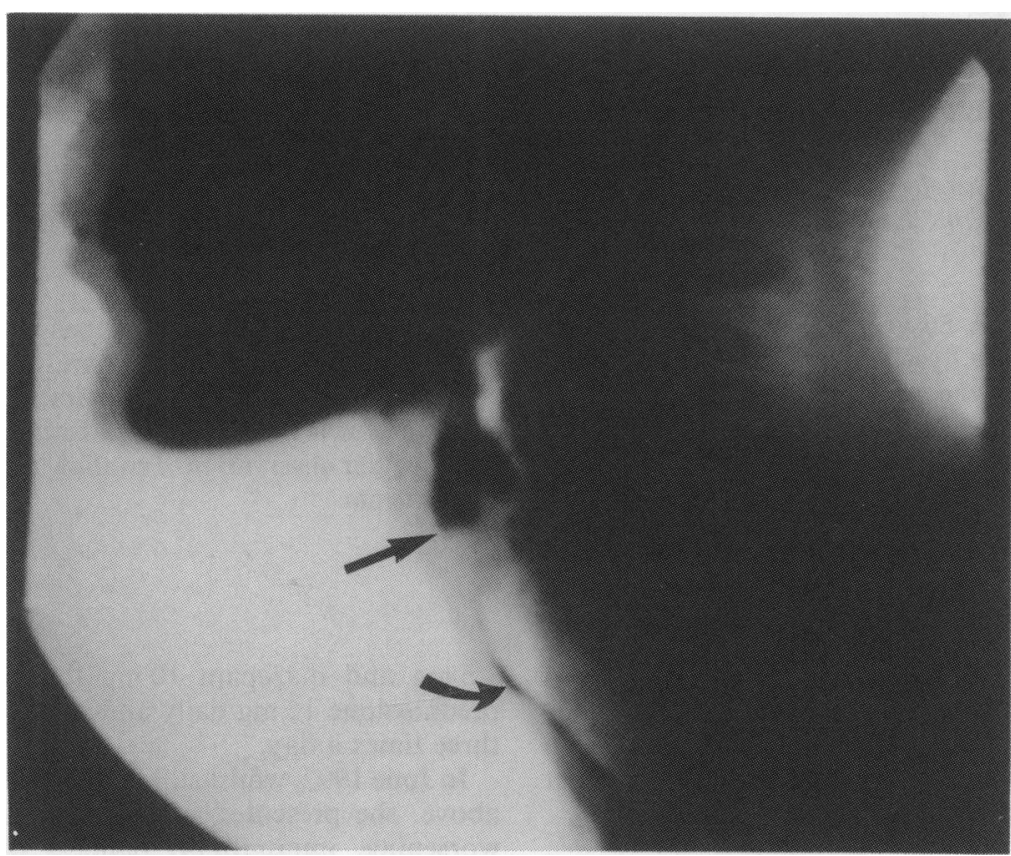

Figure 1 Videofluoroscopy image showing gross pooling in the pyriform fossae (straight arrow), failure of opening of the cricopharyngeus and tracheal aspiration (curved arrow).

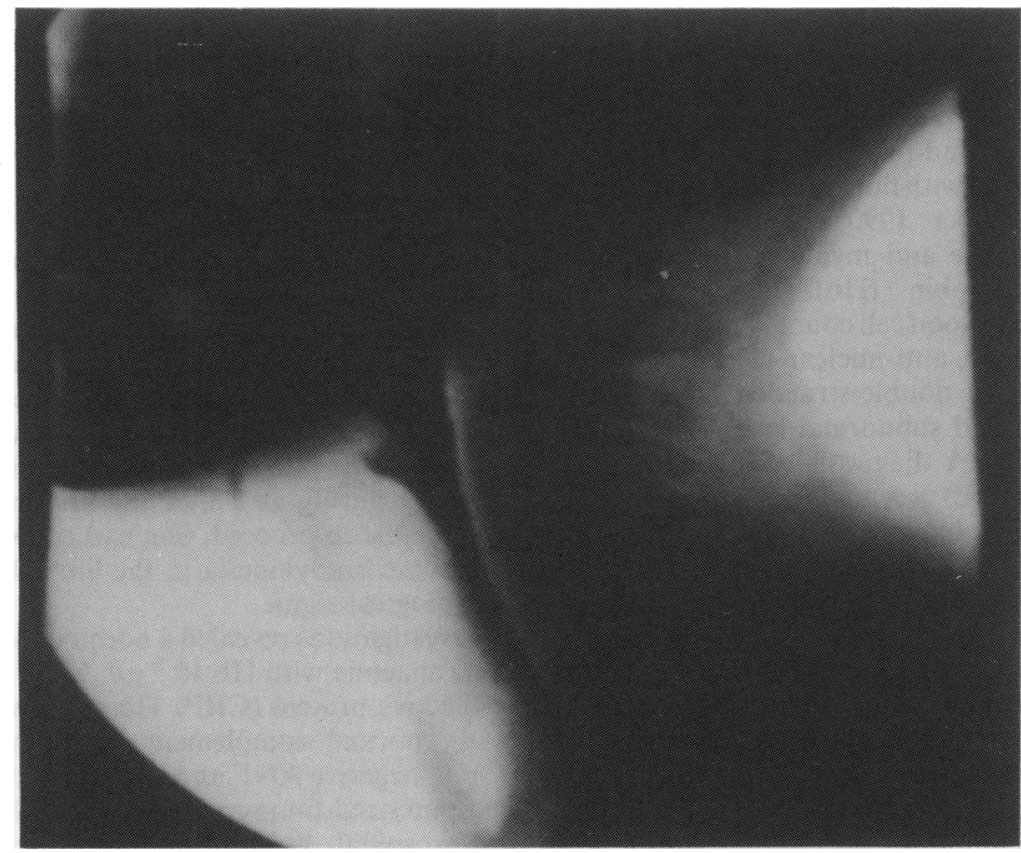

Figure 2 Repeat videofluoroscopy showing the bolus passing freely from pharynx to oesophagus without pooling or tracheal aspiration. 
In the absence of a structural lesion or of evidence of active SLE causing her dysphagia, her neuroleptic medication was suspected, particularly in view of her definite but mild extrapyramidal signs. Her case was discussed with her psychiatrist and over the next 8 days the haloperidol was stopped and the procyclidine and diazepam each reduced to $5 \mathrm{mg}$ twice a day; the dosages of other drugs were not changed. Since she had clinical and radiographic evidence of aspiration, oral feeding was stopped and a nasogastric tube used. Two weeks later she was able to swallow clear fluids. The speech therapist and dietician then gradually introduced suitable textures of food and after 6 weeks the patient was taking a normal diet without difficulty. On discharge repeat videofluoroscopy showed normal elevation of the larynx and normal opening of the cricopharyngeus without pooling or aspiration (Figure 2); ESR and CRP were normal and her weight had increased to $41.4 \mathrm{kgs}$. Despite the withdrawal of haloperidol there was an improvement in her psychiatric symptoms during this period.

\section{Discussion}

In this case a patient with SLE already on longterm flupenthixol treatment developed severe dysphagia following the addition of haloperidol, procyclidine and diazepam to her treatment. Following withdrawal of the haloperidol and a reduction in the dosage of diazepam and procyclidine the swallowing problem gradually resolved suggesting that it was the addition of haloperidol to the existing treatment that was mainly responsible for the dysphagia.

The mild signs of parkinsonism, the absence of any lower cranial nerve signs and the videofluoroscopy findings of complete failure of voluntary and reflex swallowing suggests that the drugs produced an akinesia or bradykinesia of the swallowing process; the term 'bradykinetic dysphagia' has been used by other authors to describe this type of problem. ${ }^{1}$ There was no good evidence of a dystonia of the larynx or pharynx or of tardive dyskinesia, both of which cause swallowing problems and have been associated with drugs of the major tranquillizer group. ${ }^{2,3}$ The evidence for SLE

\section{References}

1. Bazemore, P.H., Tonkonogy, J. \& Ananth, R. Dysphagia in psychiatric patients: clinical and videofluoroscopic study. Dysphagia 1991, 6: 2-5.

2. Newton-John, H. Acute upper airway obstruction due to supraglottic dystonia induced by a neuroleptic. $\mathrm{Br} \mathrm{Med} J \mathrm{~J} 1988$, 297: 964-965.

3. Massengill, R. \& Nashold, B. A swallowing disorder denoted in tardive dyskinesia patients. Acta Oto-laryngol 1969, 68: 457-458. being active during the illness was poor; the initially abnormal ESR was probably the result of lung infection secondary to aspiration as it returned to normal with management of the dysphagia alone. The small reduction in the dose of procyclidine may have contributed to the improvement seen but recovery occurred despite continuation of the drug at a dose of $10 \mathrm{mg} /$ day.

An assessment of swallowing is not routinely included in the clinical examination of patients who are on large doses of major tranquillizers despite reports suggesting an association between these drugs and unexplained fatal choking episodes in psychiatric in-patients. ${ }^{4}$ Some authors have suggested that the gag reflex should be regularly observed in patients on neuroleptic drugs thought to be at risk of developing a swallowing problem. ${ }^{5}$ If closely observed the gag reflex may give useful information about the sensory and motor innervation of the palate and the posterior pharyngeal wall, but it does not provide information about swallowing; as in this case a patient may have severe dysphagia and exhibit all the components of a normal gag reflex. For this reason observation of the patient actually swallowing is an essential part of the bedside examination; obvious caution and slowing of drinking, coughing during swallowing, an alteration in voice quality post swallow or difficulty in initiating a swallow when the bolus is held in the mouth are easily detected warning signs of impaired swallowing. Conversely, if recurrent chest infections, cough or unexplained weight loss raise the possibility of aspiration in this group of patients, a detailed clinical evaluation supported by videofluoroscopy should be carried out.

The case demonstrates the dramatic effect neuroleptic medication may have on swallowing. Dysphagia may be associated with a significant morbidity and mortality in patients on neuroleptic drugs, and a high level of clinical awareness and regular observation of the patient swallowing may help to improve detection of this problem.

\section{Acknowledgement}

We are grateful to Dr Dafydd Huws and Dr Richard Moore for permission to report details of a patient under their care, and to Dr Brian Lawrie for the videofluoroscopy images.

4. Craig, T.J. Medication use and deaths attributed to asphyxia among psychiatric patients. Am J Psychiat 1980, 137: $1366-1373$

5. Craig, T.J. \& Richardson, M.A. Swallowing, tardive dyskinesia, and anticholinergics. Am J Psychiat 1982, 138: 1083. 